\title{
Parameterizing radiative transfer to convert MAX-DOAS dSCDs into near-surface box-averaged mixing ratios
}

\author{
R. Sinreich ${ }^{1}$, A. Merten ${ }^{2, *}$, L. Molina ${ }^{3}$, and R. Volkamer ${ }^{1,4}$ \\ ${ }^{1}$ Department of Chemistry and Biochemistry, University of Colorado at Boulder, Colorado, USA \\ ${ }^{2}$ Institute for Environmental Physics, University of Heidelberg, Heidelberg, Germany \\ ${ }^{3}$ Molina Center for Energy and the Environment, La Jolla, CA, USA \\ ${ }^{4}$ Cooperative Institute for Research in the Environmental Studies, Boulder, Colorado, USA \\ *now at: Fraunhofer-Institut für Photonische Mikrosysteme, Dresden, Germany
}

Correspondence to: R. Volkamer (rainer.volkamer@colorado.edu)

Received: 31 July 2012 - Published in Atmos. Meas. Tech. Discuss.: 18 October 2012

Revised: 8 April 2013 - Accepted: 7 May 2013 - Published: 6 June 2013

\begin{abstract}
We present a novel parameterization method to convert multi-axis differential optical absorption spectroscopy (MAX-DOAS) differential slant column densities (dSCDs) into near-surface box-averaged volume mixing ratios. The approach is applicable inside the planetary boundary layer under conditions with significant aerosol load, and builds on the increased sensitivity of MAX-DOAS near the instrument altitude. It parameterizes radiative transfer model calculations and significantly reduces the computational effort, while retrieving $\sim 1$ degree of freedom. The biggest benefit of this method is that the retrieval of an aerosol profile, which usually is necessary for deriving a trace gas concentration from MAX-DOAS dSCDs, is not needed.

The method is applied to $\mathrm{NO}_{2}$ MAX-DOAS dSCDs recorded during the Mexico City Metropolitan Area 2006 (MCMA-2006) measurement campaign. The retrieved volume mixing ratios of two elevation angles $\left(1^{\circ}\right.$ and $\left.3^{\circ}\right)$ are compared to volume mixing ratios measured by two longpath (LP)-DOAS instruments located at the same site. Measurements are found to agree well during times when vertical mixing is expected to be strong. However, inhomogeneities in the air mass above Mexico City can be detected by exploiting the different horizontal and vertical dimensions probed by the MAX-DOAS and LP-DOAS instruments. In particular, a vertical gradient in $\mathrm{NO}_{2}$ close to the ground can be observed in the afternoon, and is attributed to reduced mixing coupled with near-surface emission inside street canyons. The existence of a vertical gradient in the lower $250 \mathrm{~m}$ during
\end{abstract}

parts of the day shows the general challenge of sampling the boundary layer in a representative way, and emphasizes the need of vertically resolved measurements.

\section{Introduction}

There are different ways to measure trace gases in the atmosphere. In situ techniques detect very localized trace gas information, and are able to resolve concentration gradients in plumes as air masses move across the instrument inlet. Such measurements face a challenge, which consists in how to assess representative concentrations over extended spatial scales as they are being predicted by atmospheric models and measured by satellites. In contrast, multi-axis differential optical absorption spectroscopy (MAX-DOAS) measurements integrate over a long distance and measure trace gases through the whole atmosphere (Hönninger and Platt, 2002), which inherently averages trace gas inhomogeneities. MAX-DOAS is an application of the well-established DOAS technique. DOAS uses the wavelength position and optical density of narrow band absorption features ( $<5 \mathrm{~nm}$ width) to selectively detect and quantify trace gases by applying Lambert-Beer law (Platt, 1994; Platt and Stutz, 2008). In particular, MAX-DOAS uses scattered sunlight observed from multiple viewing directions, which increases the sensitivity to trace gases close to the surface due to differences in the respective light-path distributions; this means that, in 
general, a lower "elevation angle" leads to longer light paths through a trace gas layer near the instrument altitude and thus to a stronger absorption signal (elevation angle is defined as the angle between the horizontal and the pointing direction of the telescope) (e.g., Hönninger and Platt, 2002; van Roozendael et al., 2003; Hönninger et al., 2004; Wagner et al., 2004). However, the presence of aerosols in the atmosphere can shorten (or lengthen) these light paths. The primary quantity of DOAS measurements is the differential slant column density (dSCD), which is the difference between integrated concentrations along the averaged light path of a measurement with low elevation angle and one of a reference (typically from the zenith). The light-path distribution (different photon paths from the sun through the atmosphere to the collecting telescope) of MAX-DOAS measurements is initially not known, and can be simulated with radiative transfer models. Since the dSCD value depends on the light path through the absorber layer, the knowledge of the aerosol profile, in general, is a prerequisite for the retrieval of a trace gas concentration from MAX-DOAS measurements. In contrast, long-path DOAS (LP-DOAS) uses an artificial light source whose light is commonly retro-reflected at a distance (typically up to $15 \mathrm{~km}$ ) and collected with a telescope at the place of the light source. Thus, for LP-DOAS the light path is given by twice the distance of telescope/light source and retro-reflector and therefore well defined. The LP-DOAS light beam is usually close to the surface (ca. 1-100 $\mathrm{m}$ average height) (e.g., Wang et al., 2006) and cannot be used to derive information from higher altitudes. It is still sensitive to local emissions; however, horizontal concentration gradients are inherently averaged over the light beam distance. While in theory, LP-DOAS can realize longer light paths close to the surface than MAX-DOAS (Platt and Stutz, 2008), limitations exist in the available line of sights due to the need to find appropriate places for the setup of retro-reflectors.

The conversion of MAX-DOAS dSCDs into concentrations or volume mixing ratios (VMRs) can be a challenge since the photon light paths through the atmosphere from the sun to the MAX-DOAS device are unknown. The easiest approach is the geometric approximation introduced by Hönninger and Platt (2002). However, it does not account for aerosols in the atmosphere, which can significantly influence the light paths. Approaches which consider aerosols are two-step techniques and use radiative transfer modeling (RTM), which simulates photon light paths through the atmosphere. First, the aerosol profile is derived which, then in a second step, is used to determine the trace gas profile. This has been done using optimal estimation (Rodgers, 2000; applied by, e.g., Irie et al., 2008; Inomata et al., 2008; Clemer et al., 2010), which needs a priori assumptions and can use several wavelengths for enhancing the information content of the measurement. A similar method is the regularization (Steck, 2002; applied by Prados-Roman et al., 2011). However, both methods need relatively high computational effort. Trace gas profile retrievals have also been performed by manual iteration until the RTM results match the measurement (e.g., Heckel et al., 2005). Simpler methods make certain presumptions about the profile (e.g., the height of a layer or the shape of a profile), and focus on a few key parameters (e.g., Wittrock et al., 2004; Sinreich et al., 2005; Wagner et al., 2011), which gives coarser profiles but relatively good VMR/concentration results. Here we present a new method to convert MAX-DOAS dSCDs into near-surface box-averaged VMRs in the lowest layer(s) of the planetary boundary layer (PBL). It is a one-step method and is applicable in cases when aerosols constrain the light path in a trace gas layer. The differential light path (path difference between low elevation angle and a reference with a high elevation angle) is determined, which is used to derive the trace gas VMR. Although, with this method, radiative transfer calculations are performed, the computational effort is less compared to optimal estimation profile calculations or regularization. The derived near-surface box VMRs can serve as anchors for the a priori estimates in the lowest layer of more-complex profile retrievals in order to increase computational efficiency (however, it does not provide independent information).

In the following Sect. 2 the parameterization method is described. In Sect. 3, it is applied to MAX-DOAS dSCD measurements of $\mathrm{NO}_{2}$ during the Mexico City Metropolitan Area 2006 (MCMA-2006) measurement campaign. The thus-derived VMRs obtained from MAX-DOAS measurements pointing in three different directions are compared with LP-DOAS measurements (Merten, 2008) in two (nearly opposite) horizontal directions at roof-top level.

\section{Description of the parameterization method}

MAX-DOAS performed from the ground uses the general rule that the lower the elevation angle, the higher the absorption signal for a trace gas layer located close to ground. However, the presence of an elevated aerosol load in the lowest atmospheric layer shortens the light paths. This can happen to the extent that the light-path lengths of the lowest elevation angles do not differ significantly from that of a nearby elevation angle. This incidence can be used to derive nearsurface box-averaged VMRs as shown in this paper, which often happens in a polluted environment or even in the marine boundary layer.

In a simplified way, Fig. 1 illustrates a scenario of an absorber layer (light blue) located in the PBL with a significant aerosol load close to the ground. On the right-hand side, the corresponding height concentration profile of the absorber is plotted in pink. Sunlight (yellow arrows) is reaching the atmosphere under a solar zenith angle $\vartheta$ and is scattered (indicated by red dots) considering a simplified single-scattering case (but the concept is also valid for multi-scattering cases). In the atmosphere, the sunlight is scattered either above or inside an absorber layer located in the PBL close to the ground, 


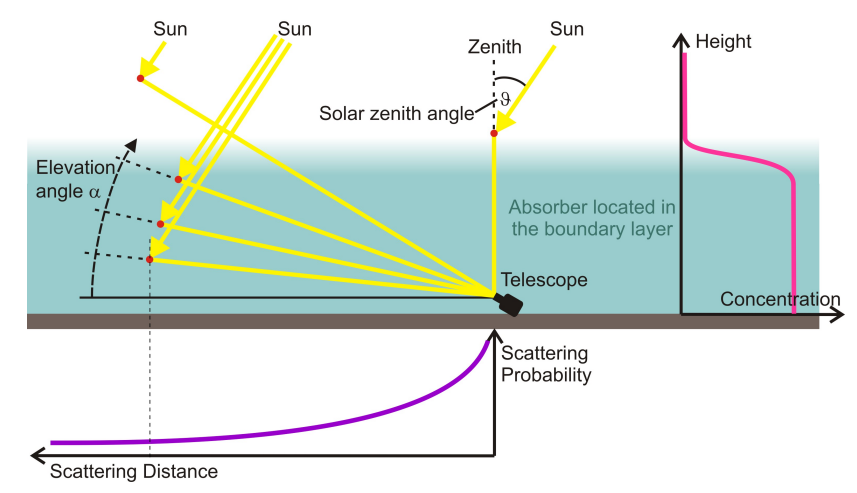

Fig. 1. Sketch of the light paths in a single-scattering case when this approach can be applied (lowest three elevation angles). Photons coming from the sun are scattered in the atmosphere (red dots) before they reach the MAX-DOAS device. An elevated aerosol load in the lowest atmosphere shortens the light path and can lead to indistinguishable dSCD values for low elevation angles. On the righthand side, the concentration profile of the absorber and, in the lower part, the photon scattering probability versus the distance from the telescope are indicated. For further information see text.

depending on the elevation angle of the measurement device. For the sunlight that is scattered above the absorber layer (indicated by the light path with the highest off-axis angle in Fig. 1) it can be expected that the dSCD signal of this absorber decreases with increasing elevation angle, which is in agreement with the traditional MAX-DOAS approach. However, if the sunlight is scattered in the absorber layer, and the aerosol load in this layer is high enough, the differences in the path lengths, which usually arise within different elevation angles, are no longer observable (indicated by the lowest three elevation angles in Fig. 1). Thus, the effective distance from the scattering events (red dots) to the telescope is about the same. Measurements in such a scenario result in dSCD values that are essentially indistinguishable from each other and independent of the choice of the elevation angle (within the analysis error) when pointing below a certain elevation angle.

In the lower part of Fig. 1, the photon scattering probability versus the distance from the telescope is qualitatively plotted in purple (Sinreich, 2008) (dotted line connecting the light path of the lowest elevation angle with the scattering probability). This should emphasize that in reality a measurement does not consist of just one single-scattering event but is composed of many scattering events overlaying each other, and follows qualitatively the scattering probability graph. Notably, the light-path length from the sun to the effective height of the scattering events of a low elevation angle is almost as long as the one for a reference spectrum to the same height (especially if the reference is acquired close in time to the measurement spectrum). Thus, the corresponding absorption signals (covering the distance from the sun to the effective height of the scattering events) in the two spectra mainly cancel out applying the DOAS method, resulting in differential effective path lengths $\left(\mathrm{d} L_{\text {eff }}\right)$. Then, the box-averaged concentration $\bar{c}$ relates to the $\mathrm{dSCD}$ as follows, which, in general, is valid also for an inhomogeneous vertical profile (see also Fig. 2):

$\mathrm{dSCD}=\sum_{i} \bar{c}_{i} \cdot \mathrm{d} l_{i}=\bar{c} \cdot \mathrm{d} L_{\text {eff }}$,

with dSCD as the dSCD for the absorber, $\bar{c}_{i}$ as the mean concentration of the absorber along the differential path with the length $\mathrm{d} l_{i}$ on which photon $i$ travels.

In order to be able to quantify $\mathrm{d} L_{\text {eff }}$, the light-path distribution of a measurement must be derived. A tracer for the light-path distribution can be found in the absorption of the trace gas $\mathrm{O}_{4}$ (e.g., Wagner et al., 2004; Sinreich et al., 2005; Frieß et al., 2006). The concentration of the oxygen dimer $\mathrm{O}_{4}$ is proportional to the concentration of $\mathrm{O}_{2}$ squared (Greenblatt et al., 1990; Volkamer, 1996). Thus, the concentration profile shape is well known and is quantitatively dependent only on the air density. Changes in the dSCDs of $\mathrm{O}_{4}$ indicate changes in the state of the atmosphere (i.e., mainly aerosol load) and measurement geometry (i.e., elevation angle, relative azimuth angle to the sun and solar zenith angle), respectively.

In cases in which the $\mathrm{O}_{4} \mathrm{dSCD}$ of the lowest elevation angles are the same (referred to as collapsing of the dSCDs in the further text) the $\mathrm{O}_{4} \mathrm{dSCD}$ can be used to determine the effective light-path length in the PBL to the telescope. This path length then allows the calculation of the near-surface box-averaged VMR of the trace gas of interest according to Eq. (1). As illustrated in Fig. 2 with $\mathrm{NO}_{2}$ as example for the trace gas of interest, the dSCDs (of a low elevation angle) of $\mathrm{O}_{4}$ and $\mathrm{NO}_{2}$ are the inputs from the measurement (lefthand side). The collapsing of the $\mathrm{O}_{4} \mathrm{dSCDs}$ of the lowest elevations angles to a single value within the analysis error is a prerequisite for applying this method since this ensures that the scattering events happened at comparable distances. Then the collapsing of the $\mathrm{NO}_{2}$ dSCDs ensures that the (last) scattering events happened in the $\mathrm{NO}_{2}$ layer and that the $\mathrm{NO}_{2}$ layer can be approximated close enough to a homogeneous near-surface layer (yielding an average box profile concentration or VMR value). Thus, when applying it to measurement data, appropriate filtering is performed before further processing the data. If a non-box profile is assumed for the trace gas $\left(\mathrm{NO}_{2}\right)$, the collapsing of the trace gas is not a necessary condition, but in this case the trace gas profile shape must be known (see Supplement for a linearly decreasing profile shape). By dividing the filtered $\mathrm{O}_{4} \mathrm{dSCD}$ by the typical $\mathrm{O}_{4}$ concentration at instrument altitude $\left(c_{\mathrm{O}_{4} \text { instr }}\right)$, a differential $\mathrm{O}_{4}$ equivalent path length $L_{\mathrm{eq}, \mathrm{O}_{4}}$ is calculated:

$L_{\mathrm{eq}, \mathrm{O}_{4}}=\frac{\mathrm{dSCD}_{\mathrm{O}_{4}}}{c_{\mathrm{O}_{4} \text { instr }}}$.

Here it is assumed that the $\mathrm{O}_{4}$ concentration does not change significantly between the altitude of the instrument and the 


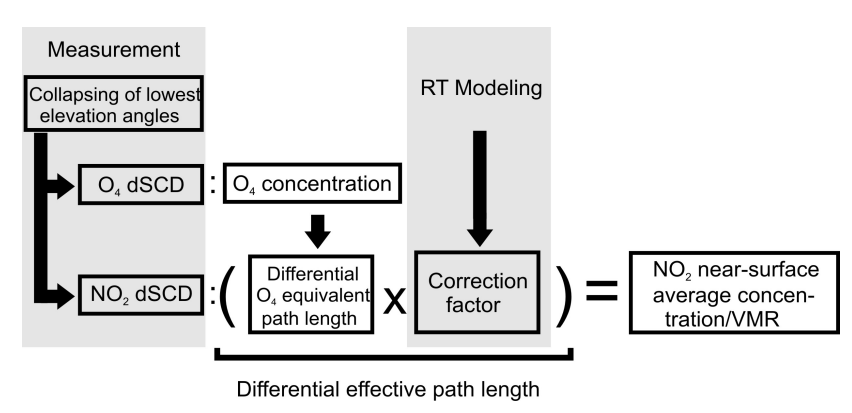

Fig. 2. Retrieval algorithm with $\mathrm{NO}_{2}$ as example for the trace gas of interest.

effective scattering event. The differential $\mathrm{O}_{4}$ equivalent path length is the light-path length from the effective scattering event to the telescope if $\mathrm{O}_{4}$ and the trace gas $\left(\mathrm{NO}_{2}\right)$ had the same concentration profile shape (here a box profile), which typically is not the case. In a next step, radiative transfer modeling is performed in order to calculate a correction factor that accounts for the different vertical profile shapes of the exponentially decreasing $\mathrm{O}_{4}$ concentrations with height and the homogenous layer for $\mathrm{NO}_{2}$ (Volkamer et al., 2009). In addition, the correction factor can account for different absorbing wavelengths of the two gases. Multiplication of the differential $\mathrm{O}_{4}$ equivalent path length with the correction factor yields the differential effective path length. Dividing the $\mathrm{NO}_{2}$ dSCD by the differential $\mathrm{NO}_{2}$ effective path length leads to the average $\mathrm{NO}_{2}$ concentration or VMR in a box that reaches from the ground to height $h_{\text {eff }}$ :

$h_{\text {eff }}=\mathrm{d} L_{\text {eff }} \cdot \sin \alpha$,

with $\alpha$ as the elevation angle.

The correction factor $f_{\mathrm{c}}$ is calculated as the ratio of the trace gas $\left(\mathrm{NO}_{2}\right)$ concentration that is retrieved by radiative transfer calculations if $L_{\mathrm{eq}, \mathrm{O}_{4}}$ is used as path length $\left(c_{\text {retrieved }}\right)$ and the trace gas concentration that is input for the radiative calculations $\left(c_{\text {real }}\right)$, which is considered to be the real concentration:

$f_{\mathrm{c}}=\frac{c_{\text {retrieved }}}{c_{\text {real }}}=\frac{\frac{\mathrm{dSCD}_{\mathrm{NO}_{2}}}{L_{\mathrm{eq}, \mathrm{O}_{4}}}}{\frac{\mathrm{VCD} \mathrm{NO}_{2}}{\mathrm{PBLh}}}$,

where $\mathrm{dSCD}_{\mathrm{NO}_{2}}$ is the retrieved $\mathrm{NO}_{2} \mathrm{dSCD}$ calculated from a radiative transfer model for a specific solar zenith angle, elevation angle, wavelength, $\mathrm{NO}_{2}$ vertical profile etc., and $\mathrm{VCD}_{\mathrm{NO}_{2}}$ and PBLh are the $\mathrm{NO}_{2}$ vertical column density (VCD) and the PBL height.

The differential air mass factor (dAMF) is defined as the ratio of the differential slant (dSCD) and vertical column density (VCD), where the latter one is the integrated concentration over the height. The AMF is a measure for the lightpath enhancement compared to the vertical path through the atmosphere. Together with Eq. (2) follows

$f_{\mathrm{c}}=\frac{\mathrm{dAMF} \mathrm{NO}_{2} \cdot \mathrm{PBLh} \cdot c_{\mathrm{O}_{4} \text { instr }}}{\mathrm{dAMF}_{\mathrm{O}_{4}} \cdot \mathrm{VCD}_{\mathrm{O}_{4}}}$,

where $\mathrm{dAMF}_{\mathrm{NO}_{2}}$ and $\mathrm{dAMF}_{\mathrm{O}_{4}}$ are the dAMFs for $\mathrm{NO}_{2}$ and $\mathrm{O}_{4}$, and $\mathrm{VCD}_{\mathrm{O}_{4}}$ is a typical $\mathrm{O}_{4} \mathrm{VCD}$ for the measurement site.

The box-averaged near-surface volume mixing ratios $\mathrm{VMR}_{\mathrm{NO}_{2}}$ can then be calculated applying the following equation:

$\mathrm{VMR}_{\mathrm{NO}_{2}}=\frac{1}{f_{\mathrm{c}}} \cdot \frac{\mathrm{dSCD} \mathrm{NO}_{2} \cdot c_{\mathrm{O}_{4}}}{\mathrm{dSCD}_{\mathrm{O}_{4}}} \cdot \frac{1}{\mathrm{CF}}$,

with dSCD $\mathrm{NO}_{2}$ and $\mathrm{dSCD}_{\mathrm{O}_{4}}$ as measured SCDs for $\mathrm{NO}_{2}$ and $\mathrm{O}_{4}$, and $\mathrm{CF}$ as the conversion factor from the concentration to the VMR.

In this paper we used the radiative transfer model McArtim (Deutschmann, 2009; Deutschmann et al., 2011) for the calculation of the correction factors. Also, the modeled dSCDs (or dAMFs) underlying the correction factors are calculated by the SCD of a given elevation angle minus the reference SCD (zenith direction) at the same solar zenith angle (SZA).

The correction factor is not a constant. In general, it depends on any factor of the state of the atmosphere (aerosol optical density, PBL height, etc.) and on the measurement geometry (solar zenith angle, elevation angle, etc.). However, the correction factors of the different elevation angles show a typical dependence towards the AOD. In order to illustrate this dependence, Fig. 3 shows calculated correction factors as a function of aerosol optical density (AOD) for different elevation angles with an arbitrarily picked scenario as example $\left(477 \mathrm{~nm}, 30^{\circ} \mathrm{SZA}\right.$ and $1 \mathrm{~km}$ PBL height). For the underlying radiative transfer calculations, the trace gas profile has been chosen as a box profile with a constant mixing ratio in the PBL. The aerosol profile also has constant aerosol extinction up to the PBL height (in this paper, the trace gas layer height and the aerosol layer height are assumed to be the same unless it is stated otherwise). The trace gas is chosen to be a weak absorber, which absorbs at the $\mathrm{O}_{4}$ wavelength of $477 \mathrm{~nm}$. The elevation angles are $1^{\circ}, 3^{\circ}, 6^{\circ}, 10^{\circ}, 20^{\circ}$ and zenith, and the relative solar azimuth angle (i.e., the horizontal projection of the angle between sun and the measurement viewing direction, RSAA) is always $90^{\circ}$. The asymmetry parameter $(g)$ of the aerosol layer in the PBL has been chosen to be 0.68 , which is a typical value for urban aerosols. The single-scattering albedo (SSA) was set to 0.95 and the surface albedo to 0.13. Figure 3 shows that with low AOD (pristine conditions) all elevation angles have different values, and beginning with a certain AOD, aerosol forces the convergence, starting with the lowest elevation angles (considering a typical DOAS error for the dSCD of $10 \%$ ). This means that the collapsing of the dSCDs of the lowest elevation angles can be seen in the correction factors when the AOD reaches a certain value, and the collapsing with even higher elevation 


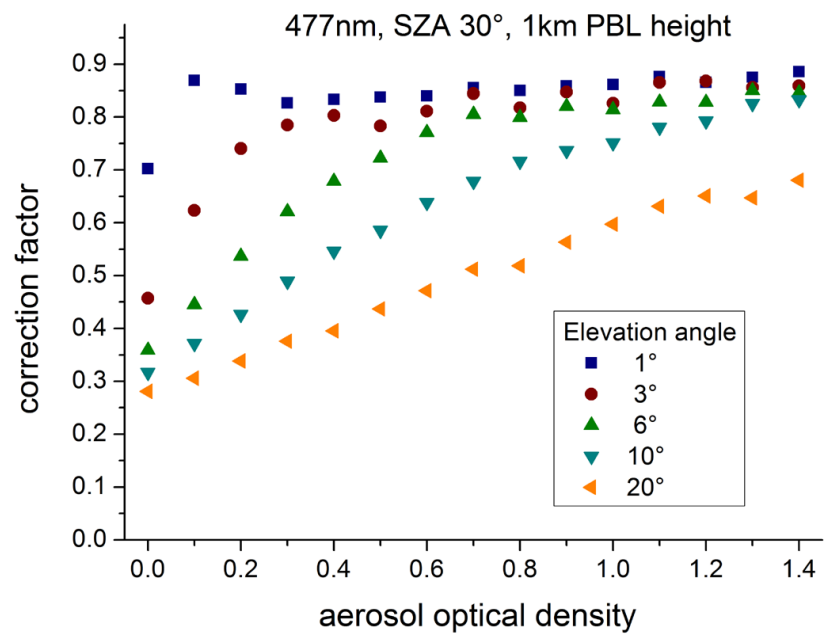

Fig. 3. Arbitrarily chosen example of calculated correction factors (for the elevation angles $1^{\circ}, 3^{\circ}, 6^{\circ}, 10^{\circ}$ and $20^{\circ}$ ) versus aerosol optical density for $477 \mathrm{~nm}, 30^{\circ} \mathrm{SZA}$ and $1 \mathrm{~km}$ PBL height (homogeneous layer for both aerosol and trace gas). With increasing aerosol load, the correction factors form a kind of plateau; the earlier the lower the elevation angle. This general behavior of the correction factors can be seen in all wavelengths, layer heights and different solar zenith angles investigated in this paper

angles happens with higher AOD values, indicating further reduced differential path lengths. Therefore, the correction factors reflect to some extent the behavior of the dSCDs. It is also observable that in the range of collapsing, the actual correction factor does not change much in value and shows a kind of plateau. This means that once convergence is observed, a further increase in aerosols has limited effect and the effective path length scales linearly with the observed $\mathrm{O}_{4}$ $\mathrm{dSCD}$. This is of big importance since, in general, the aerosol load is an important limiting factor for the interpretation of MAX-DOAS measurements.

This general behavior of the correction factors can be seen in all wavelengths, layer heights and different solar zenith angles investigated in this paper, as well as in other studies (Volkamer et al., 2009; Sinreich et al., 2010).

For the VMR retrieval, the plateau of the correction factors of a (low) elevation angle must be identified. The mean value of the plateau is taken as the corresponding correction factor (and applied to the MAX-DOAS dSCDs later). In the further text, correction factor is referred to as the AOD-independent mean value of a plateau of a certain elevation angle (and not the single correction factor value).

Figure 4 shows correction factors for the four $\mathrm{O}_{4}$ absorption bands (a) $360 \mathrm{~nm}$, (b) $477 \mathrm{~nm}$, (c) $577 \mathrm{~nm}$ and (d) $630 \mathrm{~nm}$ assuming a trace gas absorbing at the same wavelengths. For the radiative transfer calculations, the SSA is 0.78 for $360 \mathrm{~nm}$ and 0.95 for the other wavelengths (see sensitivity studies in Sect. 3). Also, the surface albedo has wavelength-dependent values: $0.09(360 \mathrm{~nm}), 0.13(470 \mathrm{~nm}), 0.17(577 \mathrm{~nm})$ and 0.2
$(630 \mathrm{~nm})$ (Barnard et al., 2008). A range of 0.3 to 0.6 AOD was chosen to determine the mean values. It is useful to set also an upper limit of the AOD because, due to applying ratios of differential values, the noise in the RTM calculation overlaying the correction factors increases with increasing AOD. Additionally, in some cases a small slope even in the plateau range could be observed, which could be due to multiple scattering in the lowest layer. Thus, unrealistically high AOD values should not be considered in this method; however, if the upper limit is chosen too low, it only has a small effect on the value of the correction factor.

The correction factors in Fig. 4 are plotted versus SZA and are derived from $3^{\circ}$ elevation angle data for the layer heights of $0.5,1$ and $2 \mathrm{~km}-$ i.e., constant trace gas mixing ratios up to the corresponding height (box profile). In order to create a diurnal plot, the morning values of the solar zenith angle are negative. Yet the values are symmetric towards $0^{\circ} \mathrm{SZA}$, showing "tooth shapes" (caused by the pronounced forward scattering on aerosols in the zenith reference). This symmetry is owing to the constant azimuth angle, and as shown in Sect. 3.1, the plot can become significantly asymmetric with changing azimuth angle (or changing layer height, or both). The errors represent the statistical error, i.e., the standard deviation within the plateaus. It can be seen that, for most SZA, the correction factors vary within $\pm 20 \%$ in the worst case $(500 \mathrm{~m}$ and $360 \mathrm{~nm})$. For a $2 \mathrm{~km}$ layer at $630 \mathrm{~nm}$ the variation is very small $( \pm 5 \%)$. Also, the higher the layer and the larger the wavelength, the less sensitive the correction factors become towards the actual layer height. The relative difference of the correction factor between different layer heights is largest for the shortest wavelength at $360 \mathrm{~nm}$. A doubling from $0.5 \mathrm{~km}$ to $1 \mathrm{~km}$ leads to an increase by a factor of 1.3 to 1.5 and from $1 \mathrm{~km}$ to $2 \mathrm{~km}$ by a factor of 1.2 to 1.3 during the day $\left(\mathrm{SZA} \leq 70^{\circ}\right)$. For $630 \mathrm{~nm}$, the corresponding factors are 1.0 to 1.2 and 1.0 to 1.1 , which are much lower.

These correction factors are calculated for clear-sky conditions. In the case of clouds directly above the PBL, the correction factors tend towards unity (independently of the layer height).

Also, it can occur that the aerosol layer and the trace gas layer are decoupled in the way that the aerosol layer extends to higher altitudes than the trace gas layer (e.g., in the case of a residual layer from the previous day(s) that is depleted in emission-related reactive gases such as $\mathrm{NO}_{2}$ ). Figure 5 shows correction factors of such a scenario (which are retrieved the same way as before): while the trace gas box profile layer height $\left(\mathrm{NO}_{2}\right)$ is always fixed to $500 \mathrm{~m}$, the box profile aerosol layers are assumed for different heights of $500 \mathrm{~m}, 1000 \mathrm{~m}, 2000 \mathrm{~m}$ and $3000 \mathrm{~m}$ (thick lines) for three different $\mathrm{SZA}\left(20^{\circ}, 50^{\circ}\right.$ and $\left.80^{\circ}\right)$. For comparison, the dotted lines represent the scenario that the $\mathrm{NO}_{2}$ layer extends to the same height as the aerosol layer; this means that both layer heights are $500 \mathrm{~m}, 1000 \mathrm{~m}, 2000 \mathrm{~m}$ or $3000 \mathrm{~m}$. These calculations were made for the MCMA-2006 case study (assuming an RSAA of $90^{\circ}$ ), which is described in the next chapter. 

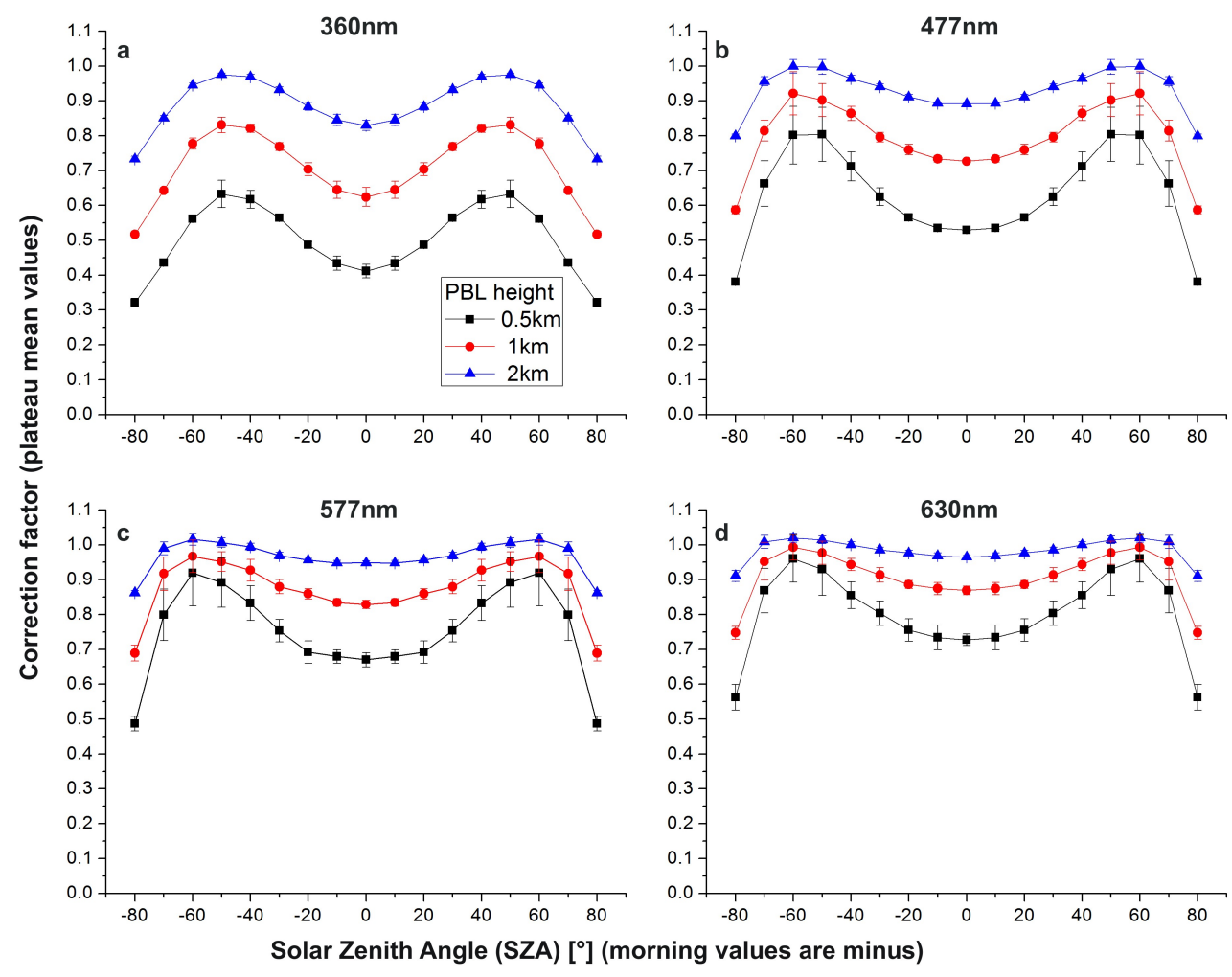

Fig. 4. Correction factor mean values for different PBL heights $(0.5 \mathrm{~km}, 1 \mathrm{~km}$ and $2 \mathrm{~km})$ and for the wavelengths (a) $360 \mathrm{~nm}$, (b) $477 \mathrm{~nm}$, (c) $577 \mathrm{~nm}$ and (d) $630 \mathrm{~nm}$ versus solar zenith angle. An AOD range between 0.3 and 0.6 ( $3^{\circ}$ elevation angle) was used to derive the mean values. For further discussion see text.

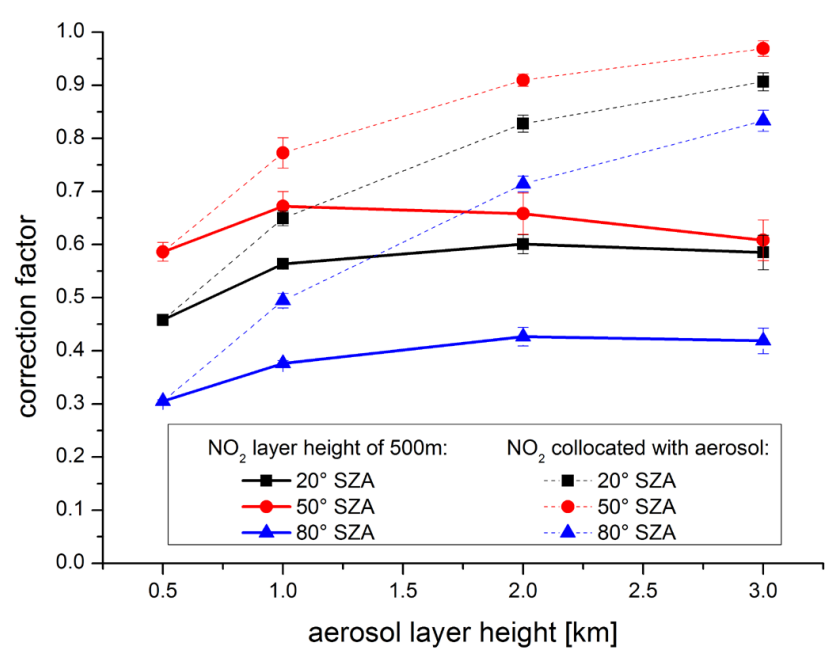

Fig. 5. Correction factors in the case of a fixed $\mathrm{NO}_{2}$ layer height of $500 \mathrm{~m}$ and a more extended aerosol layer up to $3000 \mathrm{~m}$ (thick lines) for $20^{\circ}, 50^{\circ}$ and $80^{\circ} \mathrm{SZA}$ for the MCMA-2006 case study. The dotted lines represent the original scenario of collocated layers.

Comparing the thick lines with the dotted ones, it is obvious that the correction factors of a fixed trace gas layer do not follow the increase of the correction factors of expanding collocated layers to the same extent. The increase is much more moderate $(<30 \%)$ when the trace gas layer is fixed to $500 \mathrm{~m}$ and only the aerosol layer expands. In the case of $50^{\circ} \mathrm{SZA}$, this increase is even smaller than $15 \%$. In contrast, the increase of the correction factors of collocated layers is smaller than $65 \%$ for $\mathrm{SZA}=50^{\circ}$ and smaller than $170 \%$ for $\mathrm{SZA}=80^{\circ}$. For $20^{\circ} \mathrm{SZA}$ the correction factor doubles with a (trace gas and aerosol) layer increase from $500 \mathrm{~m}$ to $3000 \mathrm{~m}$. This shows that the main determinant is the trace gas layer, and that the actual height of a larger aerosol layer plays a secondary role.

While this method largely eliminates the sensitivity to the AOD, the sensitivity towards other parameters of the atmospheric state and measurement geometry still applies. The variability of the correction factor is investigated in more detail in the next chapter with the MCMA-2006 MAX-DOAS measurements as example.

\section{MCMA-2006 case study}

\subsection{Correction factors for the MCMA-2006 MAX-DOAS setup}

The correction factors in this section are calculated for the example of Mexico City, which is located at about $2200 \mathrm{~m}$ above sea level. In 2006, during the MCMA-2006 
measurement campaign, MAX-DOAS measurements were performed at the "T0 site" at about $16 \mathrm{~m}$ height on the roof top of the Instituto Mexicano del Petroleo (IMP, a four-level building), which is located at the north edge of downtown Mexico City. The retrieved dSCDs of $\mathrm{NO}_{2}$ and $\mathrm{O}_{4}$ of $1^{\circ}$ and $3^{\circ}$ elevation angle are applied to the parameterization method after they were filtered with regard to overlapping. For both species, an uncertainty in the dSCDs of $10 \%$ is tolerated. For the calculation of the correction factors the radiative transfer model McArtim is initiated using values for surface albedo (0.09), single-scattering albedo (0.78) and asymmetry parameter $(0.68)$ as measured for urban pollution in Mexico City (Barnard et al., 2008). The $\mathrm{O}_{4}$ dSCD is retrieved from the $360 \mathrm{~nm}$ absorption band and the $\mathrm{NO}_{2} \mathrm{dSCD}$ from a DOAS fitting in wavelength range between $368 \mathrm{~nm}$ and $390 \mathrm{~nm}$.

For the example of the MCMA-2006 measurements, an AOD between 0.3 and 0.6 is a good range for layer heights from $500 \mathrm{~m}$ to $3000 \mathrm{~m}$ to reflect the overlapping of the observed $1^{\circ}$ and $3^{\circ}$ elevation angles. Also, at times, overlapping of higher elevation angles could be observed for both $\mathrm{O}_{4}$ and $\mathrm{NO}_{2}$, indicating a higher AOD. However, due to the plateau formation, a higher AOD typically has only a small effect on the correction factor. Therefore, mean values over the mentioned AOD range were used as correction factors, which are applied to the MAX-DOAS dSCDs in Sect. 3.2.

For this method, it is necessary to know or at least estimate the PBL height. Mexico City is known for its dynamic PBL, and in extreme cases of PBL variability, the correction factor can vary by a factor of 3 over the course of a day. As shown in the last section, accurate knowledge of PBL height is more crucial in the morning when the PBL height is lower. Here, a typical diurnal PBL height cycle was estimated to be about 500 m until 09:00 (local time), then to rise up constantly until $2500 \mathrm{~m}$ at 15:00. and stay at this height until the end of the day (see inset of Fig. 6). This is compatible with measurements of the PBL made by de Foy et al. (2005) in MCMA-2003 and by K. Knupp and D. Phillips from The National Space Science \& Technology Center of the University of Alabama at Huntsville in MCMA-2006. The measurement method of K. Knupp and D. Phillips is based on a ground-based RADAR profiler, and is described in Knupp et al. (2006).

For the MCMA-2006 case study, the variability of the correction factor is investigated in some more detail. While this method largely eliminates the sensitivity to the AOD the sensitivity towards other parameters of the state of the atmosphere and measurement geometry still applies, as seen above for the case of the PBL height. Most important parameters are here RSAA, surface albedo (SA), $g$ and SSA. Table 1 lists the relative change of the correction factor of the three latter parameters for different PBL heights (PBLh) and SZA when applying the corresponding parameter and leave the others at standard values $(\mathrm{SA}=0.09 ; g=0.68$; SSA $=0.78$ ). The error is a statistical error resulting from the

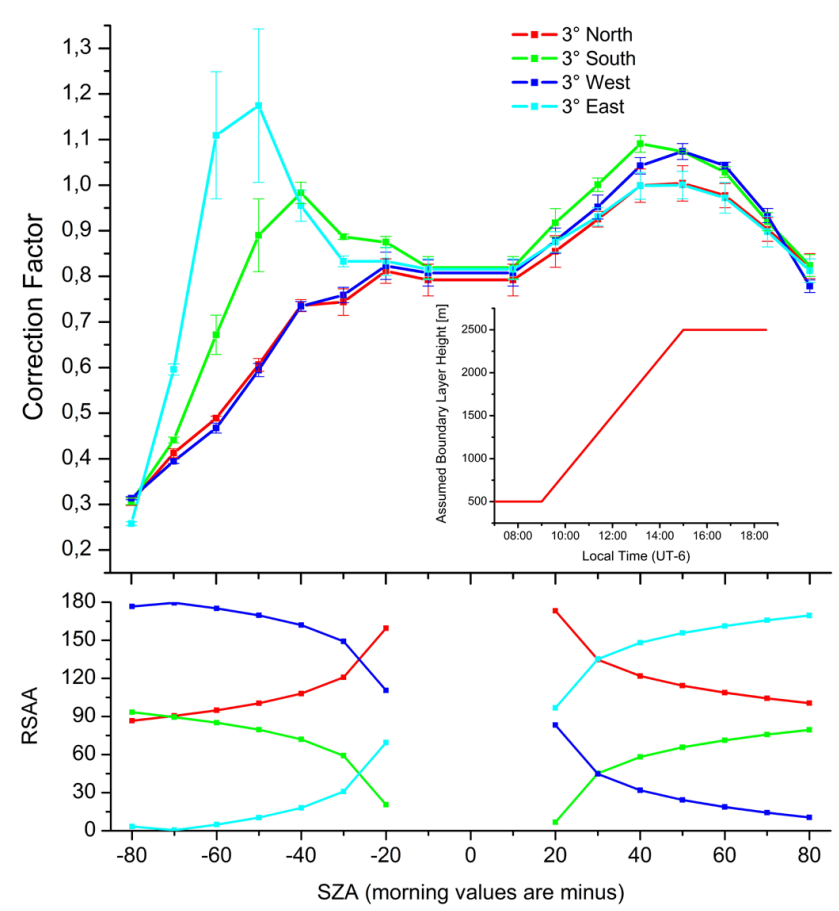

Fig. 6. Diurnal cycle of the correction factors (upper panel) considering RSAA (lower panel) and a dynamic diurnal PBL typical for Mexico City (see inset) for four different directions perpendicular to each other.

standard deviations when retrieving the plateau values. The RSAA, which is important since aerosols scatter light preferably in forward direction, is investigated separately further below.

As can be seen, all virtual changes are below $10 \%$, and thus only play a minor role for the derivation of the mixing ratios. An exception is the asymmetry parameter for low layer heights for which changes are smaller than $15 \%$.

The dependence of the correction factor on the RSAA was considered for the MCMA-2006 MAX-DOAS setup specifically. The MAX-DOAS measurements collected light simultaneously from the north, west and south (about $7^{\circ}$ rotated clockwise to the exact geographical directions). The radiative transfer calculations were made with the corresponding RSAA depending on the time of the day. The correction factors considering azimuth effect and diurnal PBL dynamics are plotted in Fig. 6 (upper panel) versus the SZA (morning values are minus). No measurements were performed in east direction, but calculations in east direction are added here to demonstrate the azimuth effect. While in the afternoon the correction factors of all 4 directions in Fig. 6 are very similar, they show significant differences when PBL and RSAA are low (east and south in the morning). The north and west direction values show a morning increase (also due to the expansion of the PBL) that is hardly affected by an azimuth effect. The lower panel of Fig. 6 illustrates the RSAAs for the four directions. Since the lowest SZA during 
Table 1. Correction factor sensitivities to surface albedo (SA), asymmetry parameter $g$ and single-scattering albedo (SSA) when modifying the corresponding parameter (default values: $\mathrm{SA}=9 \% ; g=0.68 ; \mathrm{SSA}=0.78$ ).

\begin{tabular}{llrrrrr}
\hline PBLh $[\mathrm{m}]$ & SZA $\left[{ }^{\circ}\right]$ & $\mathrm{SA}=4 \%$ & $\mathrm{Sa}=14 \%$ & $g=0.61$ & $g=0.75$ & $\mathrm{SSA}=0.95$ \\
\hline 500 & 20 & $-(4.0 \pm 2.2) \%$ & $+(3.1 \pm 2.3) \%$ & $+(13.3 \pm 3.1) \%$ & $-(9.5 \pm 2.1) \%$ & $-(0.8 \pm 3.1) \%$ \\
& 50 & $-(4.8 \pm 3.6) \%$ & $+(2.9 \pm 5.2) \%$ & $+(7.8 \pm 4.8) \%$ & $-(11.2 \pm 5.0) \%$ & $+(0.5 \pm 3.4) \%$ \\
& 80 & $-(0.8 \pm 1.8) \%$ & $+(4.0 \pm 3.8) \%$ & $+(5.0 \pm 1.6) \%$ & $-(3.7 \pm 2.2) \%$ & $+(7.7 \pm 2.5) \%$ \\
\hline \multirow{2}{*}{1000} & 20 & $-(2.9 \pm 1.7) \%$ & $+(1.5 \pm 2.4) \%$ & $+(7.5 \pm 2.4) \%$ & $-(5.3 \pm 1.6) \%$ & $-(1.4 \pm 2.2) \%$ \\
& 50 & $-(3.6 \pm 2.2) \%$ & $+(2.8 \pm 1.2) \%$ & $+(7.3 \pm 4.0) \%$ & $-(4.8 \pm 2.5) \%$ & $+(1.4 \pm 2.3) \%$ \\
& 80 & $-(0.6 \pm 1.1) \%$ & $+(0.8 \pm 1.8) \%$ & $+(3.1 \pm 2.5) \%$ & $-(2.9 \pm 2.0) \%$ & $+(4.0 \pm 3.3) \%$ \\
\hline 2000 & 20 & $+(0.3 \pm 1.3) \%$ & $+(1.9 \pm 1.7) \%$ & $+(4.2 \pm 2.2) \%$ & $-(1.5 \pm 1.8) \%$ & $-(0.1 \pm 1.0) \%$ \\
& 50 & $-(4.0 \pm 1.5) \%$ & $-(1.2 \pm 1.4) \%$ & $-(2.1 \pm 2.5) \%$ & $-(5.2 \pm 1.8) \%$ & $-(1.9 \pm 1.6) \%$ \\
& 80 & $-(1.0 \pm 1.6) \%$ & $+(0.3 \pm 1.3) \%$ & $+(0.9 \pm 1.8) \%$ & $-(1.8 \pm 2.1) \%$ & $+(1.5 \pm 3.1) \%$ \\
\hline 3000 & 20 & $-(1.0 \pm 1.4) \%$ & $-(0.5 \pm 1.0) \%$ & $+(0.7 \pm 0.7) \%$ & $-(1.0 \pm 0.3) \%$ & $-(1.7 \pm 1.2) \%$ \\
& 50 & $+(0.9 \pm 0.5) \%$ & $+(1.9 \pm 1.8) \%$ & $+(1.8 \pm 1.4) \%$ & $+(0.8 \pm 2.5) \%$ & $+(1.0 \pm 1.2) \%$ \\
& 80 & $-(0.6 \pm 0.9) \%$ & $-(1.1 \pm 0.6) \%$ & $-(0.6 \pm 2.2) \%$ & $(0.0 \pm 2.1) \%$ & $+(0.3 \pm 2.7) \%$ \\
\hline
\end{tabular}

the measurement campaign was around $15^{\circ}$, no values for the RSAA at $-10^{\circ}$ and $+10^{\circ}$ are available. Thus, for the calculation of the $\pm 10^{\circ}$ SZA correction factors, the RSAA mean values of $-20^{\circ}$ and $+20^{\circ}$ were taken.

Figure 6 shows that measuring towards the sun has a larger effect on the correction factors the lower the PBL is. This is qualitatively consistent with the $g$ dependence on the PBL height shown in Table 1.

\subsection{Determination of MAX-DOAS VMRs and comparison with LP-DOAS during MCMA-2006}

The correction factors from Fig. 6 were used to convert the $\mathrm{NO}_{2}$ dSCDs into $\mathrm{NO}_{2} \mathrm{VMRs}$ by means of corresponding $\mathrm{O}_{4}$ dSCDs using $1^{\circ}$ and $3^{\circ}$ elevation angle and applying Eq. (5). The dSCDs were retrieved by analyzing the spectra relative to the closest zenith reference measured prior to the acquisition of the measurement spectrum. Also, the corresponding ring spectrum was used so that reference and ring spectrum were continuously updated. For 3 arbitrary days (23-25 March 2006), the dSCDs in south direction are plotted in Fig. 7 for (b) $\mathrm{NO}_{2}$ and (c) $\mathrm{O}_{4}$. The overlapping of the lowest elevation angles can be seen clearly. Figure 7a shows the corresponding mixing ratio time series of MAX-DOAS in south direction for the same days. Thereby only dSCDs were used that fulfill the detection limit. It was set to 2 times the root mean square of the fit residual divided by the strongest convolved (differential) cross-section peak in the respective analysis wavelength window. Additionally, only dSCDs were considered whose spectra were acquired at SZA not larger than $80^{\circ}$. Also, VMR values of two LP-DOAS measurements from the same site pointing to the south and to the northwest with retro-reflectors at about $2.6 \mathrm{~km}$ and $1 \mathrm{~km}$ distance, respectively, are shown in Fig. 7a (Merten, 2008). During daylight (SZA $<90^{\circ}$, lightyellow background in Fig. 7a), a general agreement in the
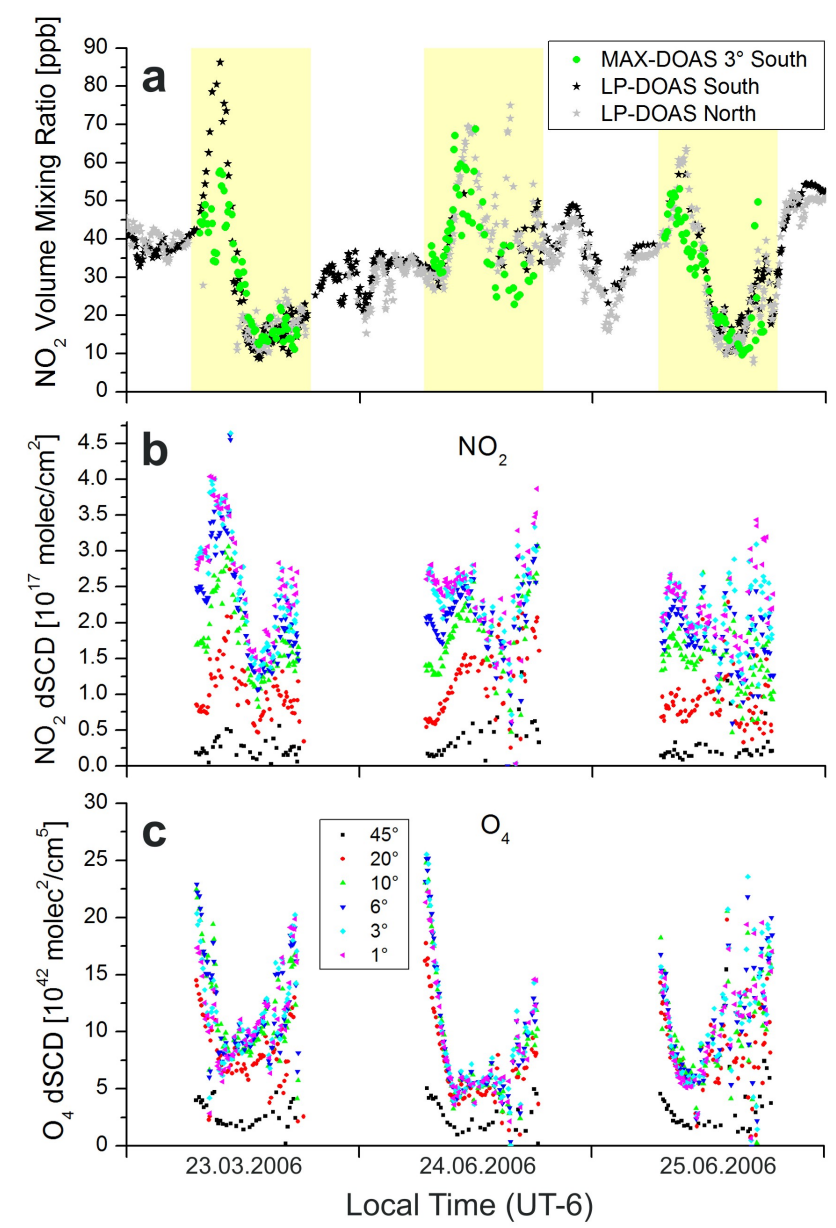

Fig. 7. (a) Comparison of MAX-DOAS pointing south and LPDOAS pointing south and northwest for 3 arbitrary days. The light-yellow background indicates daylight $\left(\mathrm{SZA}<90^{\circ}\right)$. The corresponding dSCDS for (b) $\mathrm{NO}_{2}$ and (c) $\mathrm{O}_{4}$ are shown in the panels below. 

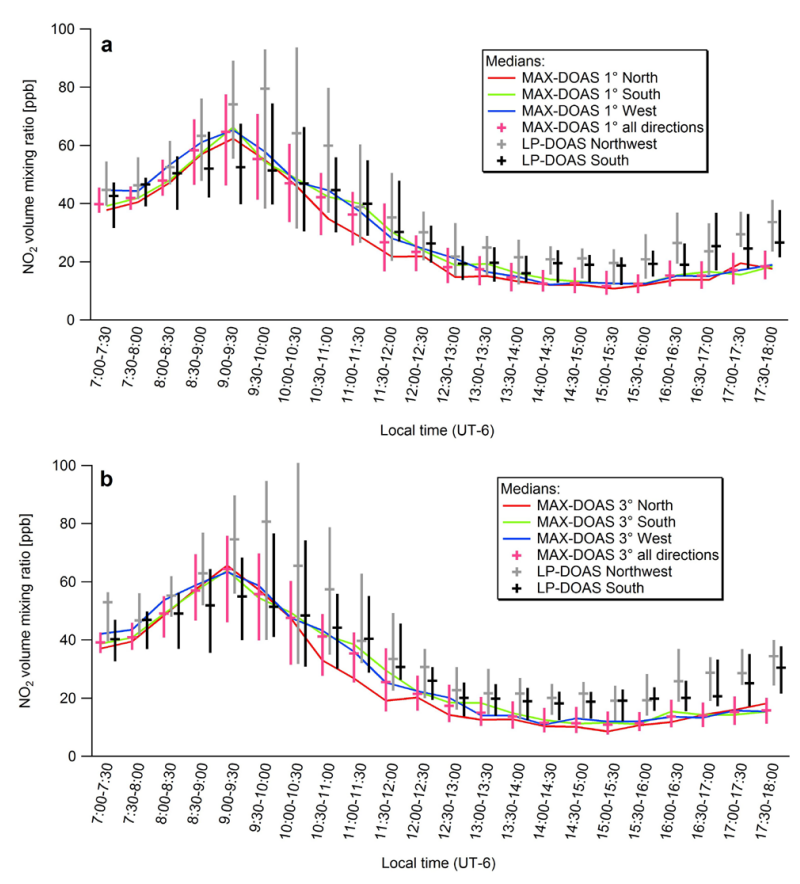

Fig. 8. Median diurnal profile (23 days) of $\mathrm{NO}_{2}$ mixing ratios measured by MAX-DOAS in three directions and by LP-DOAS in two directions, comparing MAX-DOAS data from (a) $1^{\circ}$ and (b) $3^{\circ} \mathrm{el}-$ evation angle as whiskers (crosses indicate medians; vertical extensions the 25 and 75 percentiles of the values). The lines are the median values for the different MAX-DOAS directions.

shape can be seen. However, for MAX-DOAS the peak on 23 March is not as high as for LP-DOAS. LP-DOAS shows in average about 1.7 times more $\mathrm{NO}_{2}$ than MAX-DOAS. At the time of the peak (09:35), the PBL was assumed to be about $700 \mathrm{~m}$. The layer height in this approach would have needed to be around $300 \mathrm{~m}$ in order to match the $\mathrm{NO}_{2} \mathrm{VMR}$ of LP-DOAS. Assumably, this difference is mostly a vertical inhomogeneity. On 24 March some scatter can be seen for both MAX-DOAS and the two LP-DOAS. Also, differences between the two LP-DOAS are observable several times, indicating horizontal inhomogeneities.

In order to assess the diurnal behavior for the overall time series, in the following, half-hourly medians are taken for the time when all three instruments conducted measurements (10 March-1 April 2006). Figure 8 compares the mixing ratios of MAX-DOAS of all directions and of LP-DOAS of both directions each for $1^{\circ}$ (upper panel) and $3^{\circ}$ (lower panel). The values are plotted as whiskers with crosses indicating medians, and vertical extensions the 25 and 75 percentiles of the values. The MAX-DOAS whiskers represent the statistics from all three viewing directions. Additionally, the values of the individual MAX-DOAS directions are plotted as lines, which show a small horizontal variability only between 10:30 and 12:30 in both $1^{\circ}$ and $3^{\circ}$. For the rest of the median diurnal profile, the values of the 3 directions lie mainly on top of each other, which is a confirmation of the calculated azimuth effect shown in Fig. 6. In general, the MAX-DOAS and LP-DOAS values show good agreement. However, the LP-DOAS has significantly higher values than MAX-DOAS in the afternoon, when the mixing in the PBL is less active and $\mathrm{O}_{3}$ concentrations are typically high (Volkamer et al., 2010). This is slightly more pronounced in the case of $3^{\circ}$ elevation angle than in $1^{\circ}$ elevation angle, which indicates a vertical gradient. Also, the values of the two LPDOAS directions lie on top of each other, except for the time between 09:00 and 11:00, where the northwest direction shows up to almost double the amount of $\mathrm{NO}_{2}$ as the south direction. It is surprising that the values of the two LPDOAS directions temporarily differ by a factor of 2 although the MAX-DOAS values of the three directions mostly agree with each other. Despite the relatively strong scatter in the LP-DOAS values, it indicates that there are horizontal gradients which are not detected by MAX-DOAS. Hence, it must only happen below the MAX-DOAS line of sight of $1^{\circ}$ elevation angle, thus in the lowest couple of $10 \mathrm{~m}$ (see Fig. 10).

In Fig. 9 the horizontal (left panel) and vertical (right panel) extent of the air masses probed by the MAX-DOAS measurements for $1^{\circ}$ (upper panel) and $3^{\circ}$ (lower panel) elevation angle is plotted. This is the differential effective path length and its vertical projection (see Eq. 3), which represents the spatial fetch of the MAX-DOAS measurements. The horizontal lines indicate the distances from the light source to the respective retro-reflectors for the LP-DOAS measurements. It can be seen in Fig. 9 that until 11:00 the MAX-DOAS at the measured wavelength and the longer LPDOAS light path have about the same horizontal expansion. Due to the rising of the PBL and the involved dilution of aerosols, the differential effective path length increases continuously over the course of the day and reaches about 23 times the horizontal path during afternoons. As expected from the approach description in chapter 2 , the horizontal path length is comparable for $1^{\circ}$ and $3^{\circ}$ elevation angle.

The same general picture can be observed with the median top height of the differential effective path, $h_{\text {eff }}$, which represents the vertical extent over which the box-averaged VMR is measured. The median day starts with values for $h_{\text {eff }}$ around $40 \mathrm{~m}\left(1^{\circ}\right)$ and $130 \mathrm{~m}\left(3^{\circ}\right)$ vertical dimension increasing during the day to about a factor of 3 to reach about $100 \mathrm{~m}\left(1^{\circ}\right)$ and $300 \mathrm{~m}\left(3^{\circ}\right)$ in the afternoon. The measurements were performed on roof-top level so that these heights start at a measurement altitude of about $16 \mathrm{~m}$ above ground.

By combining Fig. 8 with Fig. 9, Fig. 10 is drawn showing median $\mathrm{NO}_{2}$ VMRs for MAX-DOAS $1^{\circ}$ and $3^{\circ}$ elevation angle as well as LP-DOAS. This is done for the south direction at a time period from 08:30-09:00 (red), 1212:30 (green), and 15:30 to 16:00 (blue). The LP-DOAS $\mathrm{NO}_{2}$ VMRs (squares) are plotted at roof-top level of $16 \mathrm{~m}$ height. The $1^{\circ}$ elevation angle MAX-DOAS VMR values (circles) are at half altitude of the effective scattering height. The highest points (triangles) are retrieved from $3^{\circ}$ elevation 

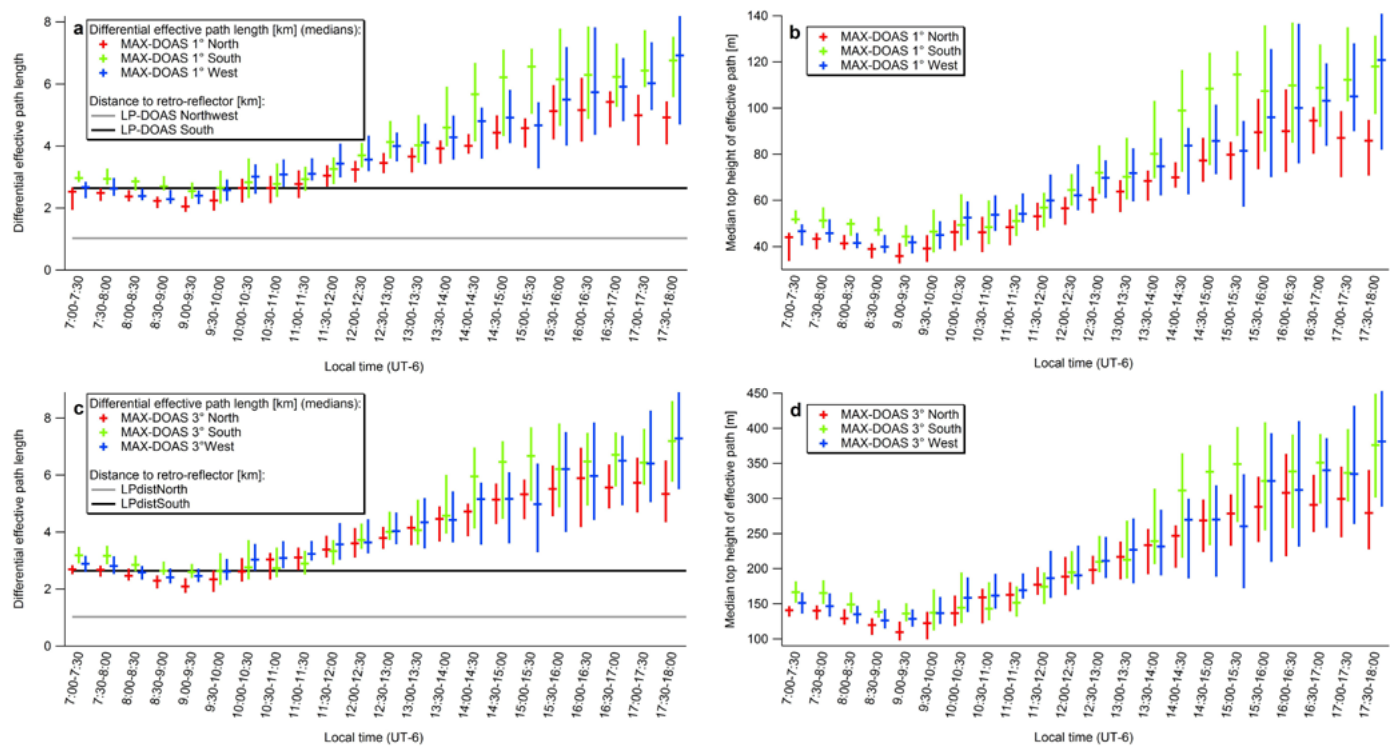

Fig. 9. Horizontal (a and $\mathbf{c})$ and vertical (b and d) expansion of the MAX-DOAS measurements for $1^{\circ}(\mathbf{a}$ and $\mathbf{b})$ and $3^{\circ}(\mathbf{c}$ and $\mathbf{d})$ elevation angle.

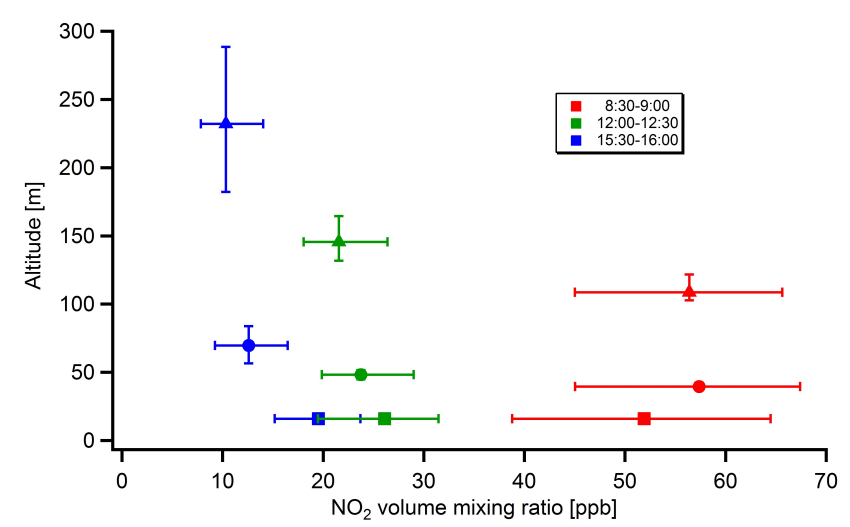

Fig. 10. $\mathrm{NO}_{2}$ volume mixing ratio altitude profiles derived from $\mathrm{LP}$ DOAS and MAX-DOAS $1^{\circ}$ and $3^{\circ}$ elevation angle values at a time period between 08:30 and 09:00 (red), 12 and 12:30 (green), and 15:30 and 16:00. (blue) in south direction.

angle MAX-DOAS data minus the $1^{\circ}$ elevation angle data weighted by the respective effective scattering heights as follows:

$\mathrm{VMR}^{*}=\frac{\operatorname{VMR}\left(3^{\circ}\right) \cdot h_{\mathrm{eff}}\left(3^{\circ}\right)-\operatorname{VMR}\left(1^{\circ}\right) \cdot h_{\mathrm{eff}}\left(1^{\circ}\right)}{h^{*}}$,

with $h^{*}$ being the height of the triangular points and the value at half height of the difference in $3^{\circ}$ elevation angle and $1^{\circ}$ elevation angle $h_{\text {eff }}$ above the $1^{\circ}$ elevation angle layer, which is $h_{\mathrm{eff}}\left(1^{\circ}\right)+\frac{h_{\text {eff }}\left(3^{\circ}\right)-h_{\text {eff }}\left(1^{\circ}\right)}{2}$. This ensures that the values in Fig. 10 represent non-overlapping layers and that only the mixing ratio retrieved in the respective layer is shown.

In the morning, a slight vertical increase between LPDOAS and MAX-DOAS can be seen that becomes a slight decrease at midday. However, the values are mostly within the error tolerance. In the afternoon, a significant vertical gradient can be observed, which halves the VMR from $16 \mathrm{~m}$ to about $240 \mathrm{~m}$ altitude, which is more pronounced closer to the ground. A similar vertical gradient was observed for toluene and $\mathrm{C}_{2}$-alkylbenzene during MCMA-2003 in Mexico City by Jobson et al. (2010) by a factor of 2 in $21 \mathrm{~m}$ difference from the ground. This might indicate that the gradient shown here also continues down to the ground.

\section{Conclusions}

A parameterization method to convert MAX-DOAS dSCDs into near-surface box-averaged VMRs is described in detail. Differential effective light paths were calculated, and correction factors are derived from radiative transfer modeling to retrieve near-surface trace gas mixing ratios. For applying this method, the aerosol load must be high enough (typically an AOD of 0.3 or higher), as indicated by the "collapsing" of $\mathrm{O}_{4} \mathrm{dSCD}$ values in the lowest elevation angles (i.e., they have about the same value). Such conditions are often found in the marine boundary layer, or in urban polluted atmospheres. Then the method is rather insensitive to the assumptions about the state of the atmosphere (aerosol extinction, phase function, surface albedo, etc.). However, especially the actual trace gas layer height and relative solar azimuth angle (RSAA) have a strong impact in cases when both RSAA and planetary boundary layer (PBL) are low. The VMRs retrieved by this method become more variable with decreasing PBL, and therefore the application of this method is not recommended for low PBL layer heights (e.g., below $500 \mathrm{~m}$ ) without knowing the actual height. 
The presented approach has in particular several advantages:

1. The approach is straightforward (a one-step conversion) and significantly reduces computational effort. It retrieves $\sim 1$ degree of freedom (near-surface volume mixing ratio), which is about half of the typical information content (between 1.8 to 2.1 degrees of freedom) that can be derived from a full inversion; see Clemer et al. (2010).

2. The approach focuses on those altitudes where MAXDOAS is maximally sensitive and least limited in information content, which is close to instrument altitude. This near-surface concentration can serve as an anchor for the a priori estimate in the lowest layer, although it does not provide independent information in the optimal estimation retrieval.

3. It only depends weakly on the aerosol layer height and not on the actual aerosol load (as long as the $\mathrm{O}_{4}$ dSCD values of the lowest elevation angles "collapse"), which is typically necessary for MAX-DOAS concentration retrievals.

4. To apply this method, the trace gas layer height is ideally known, or otherwise has to be estimated. The nearsurface VMR becomes rather insensitive of trace gas layer height if this height is $1 \mathrm{~km}$ or higher. Then, if the layer height was twice as high as assumed (e.g., $2 \mathrm{~km}$ ), the error in the VMR estimate is $30 \%$ or less. The method is most insensitive to layer height in high PBLs.

5. If the trace gas dSCDs of the lowest elevation angles "collapse" within DOAS error, the trace gas profile can be approximated reasonably as a box profile.

During the MCMA-2006 measurement campaign, two LPDOAS facing in near-opposite directions and a MAX-DOAS pointing in three directions perpendicular to each other were deployed in a systematic effort to access inhomogeneities of the Mexico City air mass. While LP-DOAS averages the trace gas concentration close to the roof top (a few meters above street canyons) with a horizontal expansion of 1 and $2.6 \mathrm{~km}$, MAX-DOAS covers a minimum spatial fetch of $40 \mathrm{~m}$ height and $2.5 \mathrm{~km}$ horizontal length in the morning $\left(1^{\circ}\right.$ elevation angle) up to a maximum of about $350 \mathrm{~m}$ height and $5 \mathrm{~km}$ length in the evening $\left(3^{\circ}\right)$. For the $3^{\circ}$ elevation angle data, as expected the vertical extension is about 3 times higher than that of the $1^{\circ}$ elevation angle data. The comparison of the LP-DOAS and MAX-DOAS values gives indication of horizontal and vertical inhomogeneities. In particular, a vertical gradient of $\mathrm{NO}_{2}$ close to the ground can be concluded in the afternoon.The comparison shows the unique potential and importance of MAX-DOAS measurements in dynamic polluted environments like megacities.

\section{Supplementary material related to this article is available online at: http://www.atmos-meas-tech.net/6/ 1521/2013/amt-6-1521-2013-supplement.pdf.}

Acknowledgements. Financial support from NSF-SGER (ATM0827386), NSF-CAREER (ATM-0847793) and CU Boulder startup funds (RV) and MCE2 (LTM) is gratefully acknowledged. We are grateful for the measurements of PBL in MCMA-2006 made by K. Knupp and D. Phillips from The National Space Science \& Technology Center of the University of Alabama at Huntsville. We are also thankful to P. Sheehy for his help in performing the LP-DOAS measurements. We thank Gustavo Sosa and local supporters at IMP for the great campaign organization, Ulrich Platt for loan of the instruments, and Thomas Wagner for helpful comments on the manuscript.

Edited by: M. Van Roozendael

\section{References}

Barnard, J. C., Volkamer, R., and Kassianov, E. I.: Estimation of the mass absorption cross section of the organic carbon component of aerosols in the Mexico City Metropolitan Area, Atmos. Chem. Phys., 8, 6665-6679, doi:10.5194/acp-8-6665-2008, 2008.

Clémer, K., Van Roozendael, M., Fayt, C., Hendrick, F., Hermans, C., Pinardi, G., Spurr, R., Wang, P., and De Mazière, M.: Multiple wavelength retrieval of tropospheric aerosol optical properties from MAXDOAS measurements in Beijing, Atmos. Meas. Tech., 3, 863-878, doi:10.5194/amt-3-863-2010, 2010.

de Foy, B., Caetano, E., Magaña, V., Zitácuaro, A., Cárdenas, B., Retama, A., Ramos, R., Molina, L. T., and Molina, M. J.: Mexico City basin wind circulation during the MCMA-2003 field campaign, Atmos. Chem. Phys., 5, 2267-2288, doi:10.5194/acp-52267-2005, 2005.

Deutschmann, T.: Atmospheric Radiative Transfer Modelling with Monte Carlo Methods, Diploma thesis, Institute of Environmental Physics, University of Heidelberg, Germany, 2009.

Deutschmann, T., Beirle, S., Frieß, U., Grzegorski, M., Kern, C., Kritten, L., Platt, U., Prados-Román, C., Pukite, J., Wagner, T., Werner, B., and Pfeilsticker, K.: The Monte Carlo atmospheric radiative transfer model McArtim: Introduction and validation of Jacobians and 3D features, J. Quant. Spectrosc. Ra., 112, 1119$1137,2011$.

Frieß, U., Monks, P. S., Remedios, J. J., Rozanov, A., Sinreich, R., Wagner, T., and Platt, U.: MAX-DOAS $\mathrm{O}_{4}$ measurements: A new technique to derive information on atmospheric aerosols: 2. Modeling studies, J. Geophys. Res., 111, D14203, doi:10.1029/2005JD006618, 2006.

Greenblatt, G. D., Orlando, J. J., Burkholder, J. B., and Ravishankara, A. R.: Absorption measurements of oxygen between 330 and 1140 nm, J. Geophys. Res., 95, 18577-18582, 1990.

Heckel, A., Richter, A., Tarsu, T., Wittrock, F., Hak, C., Pundt, I., Junkermann, W., and Burrows, J. P.: MAX-DOAS measurements of formaldehyde in the Po-Valley, Atmos. Chem. Phys., 5, 909918, doi:10.5194/acp-5-909-2005, 2005. 
Hönninger, G. and Platt, U.: The Role of BrO and its Vertical Distribution during Surface Ozone Depletion at Alert, Atmos. Environ., 36, 2481-2489, 2002.

Hönninger, G., von Friedeburg, C., and Platt, U.: Multi axis differential optical absorption spectroscopy (MAX-DOAS), Atmos. Chem. Phys., 4, 231-254, doi:10.5194/acp-4-231-2004, 2004.

Inomata, S., Tanimoto, H., Kameyama, S., Tsunogai, U., Irie, H., Kanaya, Y., and Wang, Z.: Technical Note: Determination of formaldehyde mixing ratios in air with PTR-MS: laboratory experiments and field measurements, Atmos. Chem. Phys., 8, 273284, doi:10.5194/acp-8-273-2008, 2008.

Irie, H., Kanaya, Y., Akimoto, H., Iwabuchi, H., Shimizu, A., and Aoki, K.: First retrieval of tropospheric aerosol profiles using MAX-DOAS and comparison with lidar and sky radiometer measurements, Atmos. Chem. Phys., 8, 341-350, doi:10.5194/acp-8341-2008, 2008.

Jobson, B. T., Volkamer, R. A., Velasco, E., Allwine, G., Westberg, H., Lamb, B. K., Alexander, M. L., Berkowitz, C. M., and Molina, L. T.: Comparison of aromatic hydrocarbon measurements made by PTR-MS, DOAS and GC-FID during the MCMA 2003 Field Experiment, Atmos. Chem. Phys., 10, 1989-2005, doi:10.5194/acp-10-1989-2010, 2010.

Knupp, K. R., Walters, J., and Biggerstaff, M.: Doppler Profiler and Radar Observations of Boundary Layer Variability during the Landfall of Tropical Storm Gabrielle, J. Atmos. Sci., 63, 234251, doi:10.1175/JAS3608.1, 2006.

Merten, A.: Neues Design von Langpfad-DOAS-Instrumenten basierend auf Faseroptiken und Anwendungen der Untersuchung der urbanen Atmosphäre, Ph. D. thesis, University of Heidelberg, 2008.

Platt, U.: Differential optical absorption spectroscopy (DOAS), Air monitoring by spectroscopic techniques, edited by: Sigrist, M. W., Chemical Analysis Series, 127, John Wiley \& Sons, Inc., 1994.

Platt, U. and Stutz, J.: Differential Optical Absorption Spectroscopy, PrinciplesandApplications, Springer, Berlin, 2008.

Prados-Roman, C., Butz, A., Deutschmann, T., Dorf, M., Kritten, L., Minikin, A., Platt, U., Schlager, H., Sihler, H., Theys, N., Van Roozendael, M., Wagner, T., and Pfeilsticker, K.: Airborne DOAS limb measurements of tropospheric trace gas profiles: case studies on the profile retrieval of $\mathrm{O}_{4}$ and $\mathrm{BrO}$, Atmos. Meas. Tech., 4, 1241-1260, doi:10.5194/amt-4-1241-2011, 2011.

Rodgers, C. D.: Inverse Methods for Atmospheric Sounding: Theory and Practice, Vol. 2 of Atmospheric, Oceanic and Planetary Physics, World Scientific, Hackensack, NJ, 2000.

Sinreich, R.: Multi-Axis Differential Optical Absorption Spectroscopy Measurements in Polluted Environments, Ph. D. thesis, University of Heidelberg, 2008.

Sinreich, R., Frieß, U., Wagner, T., and Platt, U.: Multi axis differential optical absorption spectroscopy (MAX-DOAS) of gas and aerosol distributions, Faraday Discuss., 130, 153-164, doi:10.1039/b419274p, 2005.
Sinreich, R., Coburn, S., Dix, B., and Volkamer, R.: Ship-based detection of glyoxal over the remote tropical Pacific Ocean, Atmos. Chem. Phys., 10, 11359-11371, doi:10.5194/acp-1011359-2010, 2010.

Steck, T.: Methods for determining regularization for atmosphericretrieval problems, Appl. Optics, 41, 1788-1797, 2002.

van Roozendael, M., Fayt, C., Post, P., Hermans, C., and Lambert, J.-C.: Retrieval of $\mathrm{BrO}$ and $\mathrm{NO}_{2}$ from UV-Visible Observations, in: Sounding the troposphere from space: a new era for atmospheric chemistry, Springer-Verlag, ISBN 3-540-40873-8, edited by: Borell, P., Borell, P. M., Burrows, J. P., and Platt, U., 2003.

Volkamer, R.: Absorption von Sauerstoff im Herzberg I System und Anwendung auf Aromatenmessungen am EUropean PHOto REactor (EUPHORE), Diploma thesis D-491, University of Heidelberg, Germany, 1996.

Volkamer, R., Coburn, S., Dix, B., and Sinreich, R.: MAX-DOAS observations from ground, ship, and research aircraft: maximizing signal-to-noise to measure "weak" absorbers, Proc. SPIE, Vol. 7462, 746203, doi:10.1117/12.826792, 2009.

Volkamer, R., Sheehy, P., Molina, L. T., and Molina, M. J.: Oxidative capacity of the Mexico City atmosphere - Part 1: A radical source perspective, Atmos. Chem. Phys., 10, 6969-6991, doi:10.5194/acp-10-6969-2010, 2010.

Wagner, T., Dix, B., v. Friedeburg, C., Frieß, U., Sanghavi, S., Sinreich, R., and Platt, U.: MAX-DOAS $\mathrm{O}_{4}$ measurements: A new technique to derive information on atmospheric aerosols - Principles and information content, J. Geophys. Res., 109, D22205, doi:10.1029/2004JD004904, 2004.

Wagner, T., Beirle, S., Brauers, T., Deutschmann, T., Frieß, U., Hak, C., Halla, J. D., Heue, K. P., Junkermann, W., Li, X., Platt, U., and Pundt-Gruber, I.: Inversion of tropospheric profiles of aerosol extinction and $\mathrm{HCHO}$ and $\mathrm{NO}_{2}$ mixing ratios from MAX-DOAS observations in Milano during the summer of 2003 and comparison with independent data sets, Atmos. Meas. Tech., 4, 2685-2715, doi:10.5194/amt-4-2685-2011, 2011.

Wang, S., Ackermann, R., and Stutz, J.: Vertical profiles of $\mathrm{O}_{3}$ and $\mathrm{NO}_{\mathrm{x}}$ chemistry in the polluted nocturnal boundary layer in Phoenix, AZ: I. Field observations by long-path DOAS, Atmos. Chem. Phys., 6, 2671-2693, doi:10.5194/acp-6-2671-2006, 2006.

Wittrock, F., Oetjen, H., Richter, A., Fietkau, S., Medeke, T., Rozanov, A., and Burrows, J. P.: MAX-DOAS measurements of atmospheric trace gases in Ny-Ålesund - Radiative transfer studies and their application, Atmos. Chem. Phys., 4, 955-966, doi:10.5194/acp-4-955-2004, 2004. 